\title{
Antimicrobial susceptibility of Clostridium difficile isolated from different sources of Imam Reza Hospital, Tabriz
}

\author{
${ }^{1}$ Mohammad Taghi Akhi, ${ }^{1 *}$ Tahere Pirzade, ${ }^{2}$ Behruz Naghili, ${ }^{3}$ and Mortaza Gojazade ${ }^{4}$ \\ ${ }^{1}$ Department of Microbiology, Faculty of Medicine, Tabriz University of Medical Science, Iran. \\ ${ }^{2}$ Department of Infectious Disease, Faculty of Medicine, Tabriz University of Medical Science, Iran. \\ ${ }^{3}$ Department of Physiology, Faculty of Medicine, Tabriz University of Medical Science, Iran.
}

Accepted 23 August, 2011

\begin{abstract}
The aim of this study was to determine antibiotic susceptibility of Clostridium difficile isolated from different sources. Two hundred stool samples of staff, patients (at admission to the wards and the same patients after seven days of hospitalization), and 135 samples of hospital environment were collected. Three standard methods including direct plating onto cycloserine-cefoxitin fructose agar, alcohol shock and enrichment culture with $0.1 \%$ sodium taurocholate were used to isolate $C$. difficile. All $C$. difficile isolates identified by biochemical tests and were tested by disk diffusion agar using 15 antibiotic disks. MIC of isolates was determined for vancomycin and metronidazol by Etest. Seventy $C$. difficile were isolated from different sources. No resistant isolates to vancomicin and metronidazol were detected by disk diffusion or Etest. The rate of recovery by $0.1 \%$ sodium taurocholate enrichment method and alcohol shock was significantly higher than those by CCFA (pv 0.02, pv 0.04).
\end{abstract}

Key words: Clostridium difficile, antibiotic resistance, vancomycin, metronidazol.

\section{INTRODUCTION}

Clostridium difficile is a Gram-positive spore forming strict anaerobic bacteria and is considered as the main etiological agent of hospital aquired diarrhoea. In the hospital environment, spores resistant to acid, chemical, and physical factors are common contaminants from hospital staff and patients who harbour $C$. difficile (Fawley and Wilcox, 2001). Approximately $20 \%$ of individuals who are hospitalized acquire $C$. difficile during hospitalization by different routes including healthy staff carrier, and more than $37 \%$ of these patients develop diarrhoea after antibiotic therapy has made the bowel susceptible to infection (McDonald et al., 2006; Macfarland et al., 1989).

The severity of infection ranges from self-limiting diarrhoea to life threatening pseudomembranous colitis

*Corresponding author. E-mail: t_pirzad@yahoo.com. Tel/fax: 98-411-3364661. (Mobile): 09141014516.1
(PMC), accounting for 15 to $25 \%$ of antibiotic-associated diarrhoea without colitis and 90 to $100 \%$ of pseudomembranous colitis associated with antibiotic use (Poxton et al., 2001; Bartlett, 1994). While treatment of asymptomatic carriers is not recommended, patients with more serious infections may require antibiotic therapy immediately. Susceptibility testing is rarely performed for C. difficile because of complexity and cost. Vancomycin and metronidazole are still the two primary antibiotics used in the treatment of $C$. difficile infection (Noren, 2010). Although susceptible $C$. difficile to vancomycin and metronidazole have been reported from many countries (Huang et al., 2009) but resistant and reduced sensitivity strains of this bacterium to these clinically important antibiotics have also been isolated (Pelaez et al., 2008, 2005; Dworczynski et al., 1991).

The aim of the present study was to determine recovery rate of $C$. difficile from different sources by three methods and to find out susceptibility patterns of $C$. difficile isolated from different sources. 


\section{METHODOLOGY}

\section{Hospital setting}

The Imam Reza hospital is situated in Tabriz city with 520 beds in 26 clinical wards, providing services for two thousand patients monthly. The hospital environment is regularly cleaned with detergent, water, and disinfectants such as Descocide by special team. Tables are usually cleaned with big spray. Hand washing with soap and water is the most common way for staff hand hygiene but Manorapid is also used. All disinfectants used are produced in Germany, the Anticeptica chem. Pharm. GmbH.

\section{Collection of specimens}

From 22 December 2009 to 20 April 2010, ten out of 26 wards of Imam Reza hospital including, nephrology, gastroenterology, pulmonology, endocrine and rheumatology, neurology, infectious disease, ICU of neurology, ICU of neurology surgery, ICU of general surgery and ICU of pulmonary were selected based on the length of patients hospitalization.

One hundred stool samples were collected from staff who had been working for at least three years in these wards. Hundred stool samples were obtained from 50 consecutive patients at first day of admission to these wards and from the same patients after seven days of hospitalization (each patient two faeces). One hundred and thirty-five samples were collected from different regions $\left(100-\mathrm{cm}^{2}\right.$ areas) of the hospital wards comprising patients' room floors $(\mathrm{n}=$ $30)$, beds $(n=30)$, doorknobs $(n=30)$, corridors $(n=10)$, toilets ( $=16)$ and keyboard of computers $(n=19)$ with thioglycolate moistened sterile cotton wool swabs in to $1 \mathrm{~mL}$ thioglycollate.

\section{Microbial investigation}

All 335 specimens were immediately transported to the laboratory of microbiology department and were processed by three techniques. Direct plating onto cycloserine- cefoxitin fructose agar (CCFA; Hi media) supplemented with $5 \%$ sheep blood, $50 \mathrm{mg} / 100$ $\mathrm{mL}$ cycloserine and $1.6 \mathrm{mg} / 100 \mathrm{~mL}$ cefoxitin (O'Connor et al., 2001), alcohol shock followed by inoculation onto colombia agar supplemented with $5 \%$ sheep blood were performed. For alcohol shock about $1 \mathrm{~g}$ of stool sample ( or $1 \mathrm{~mL}$ of environmental broth sample) was mixed with an equal volume of ethanol, gently vortex and left at room temperature for $60 \mathrm{~min}$. Samples were centrifuged at $3800 \times \mathrm{g}$ for $10 \mathrm{~min}$, the supernatant was discarded and resulting pellet was plated onto colombia agar supplemented with $5 \%$ sheep blood. The inoculated plates were incubated anaerobically (using Anoxomat: MART Microbiology B.V. the Netherlands $0 \% \mathrm{O}_{2}, 10 \%$ $\mathrm{H}_{2}, 10 \% \mathrm{CO}_{2}, 80 \% \mathrm{~N}_{2}$ ) at $37^{\circ} \mathrm{C}$ and examined daily up to 5 days. One gram of faeces or $1 \mathrm{~mL}$ environmental broth sample was also inoculated to $9 \mathrm{~mL}$ of thioglycollate supplemented with $0.1 \%$ sodium taurocholate, $50 \mathrm{mg} / 100 \mathrm{~mL}$ cycloserine, and $1.6 \mathrm{mg} / 100 \mathrm{~mL}$ cefoxitin. After seven days of incubation at $37^{\circ} \mathrm{C}, 2 \mathrm{~mL}$ was transferred into a sterile test tube and mixed with an equal amount of ethanol and the alcohol shock procedure were carried out as mentioned above. Suspicious colonies were purified by subculturing and $C$. difficile was identified by characteristic morphology of colonies, specific horse odour, green- yellow fluorescence under UV light (365 nm), Gram staining and biochemical tests (Arroyo et al., 2005; Pituch et al., 2005). Antimicrobial susceptibilities of all isolates were tested by the modified Kirby-Bauer disc diffusion method on Muller- Hinton agar supplemented with $5 \%$ sheep blood to metronidazole (MZ $5 \mu \mathrm{g}$ ), vancomycin (VA $30 \mu \mathrm{g}$ ), clindamycin (CD $2 \mu \mathrm{g}$ ), gentamicin (GM $120 \mu \mathrm{g}$ ), rifampin (RP $5 \mu \mathrm{g}$ ) chloramphenicol (C $30 \mu \mathrm{g})$, erythromycin (E15 $\mu \mathrm{g})$, tetracycline $($ T30 $\mu \mathrm{g})$, imipenem (IMI $10 \mu \mathrm{g}$ ), ciprofloxacin (CIP $5 \mu \mathrm{g}$ ), ampicillin
(AM $10 \mu \mathrm{g}$ ), piperacillin/tazobactam (PTZ 100/10 $\mu \mathrm{g}$ ), amoxicillin + clavulanic acid (AC $30 \mu \mathrm{g})$, cefotaxime (CTX $30 \mu \mathrm{g})$, colistin $(25 \mu \mathrm{g})$ (Poilane et al., 2007). MIC for vancomycin and metronidazole was determined by Etest (Biomerieux, Sweden) on Muller- Hinton agar supplemented with $5 \%$ sheep blood according to the instructions of manufacturer.

\section{RESULTS}

Out of $70 \mathrm{C}$. difficile isolates which were cultured as a first time in north west of Iran, $18 \%(18 / 100), 10.37 \%$ (14/135), 32\% (16/50) and 44\% (22/50), were isolated from Staff, hospital environment, patients at first day of admission and the same patients after seven days of hospitalization respectively. Six patients (12\%) were colonized by $C$. difficile during seven days of hospitalizations. Fourteen isolates (10.37\%) of $C$. difficile was obtained from various region of pulmonary $(n=5)$, infectious disease $(n=3)$, ICU of neurology $(n=3)$, ICU of pulmonary $(n=2)$ and endocrine and rheumatology $(n$ $=1$ ) wards. C. difficile was recovered from 11.1, 38.9, and $50 \%$ of the specimens by using CCFA, alcohol shock and $0.1 \%$ sodium taurocholate enrichment methods, respectively. The rate of recovery by $0.1 \%$ sodium taurocholate enrichment method and alcohol shock was significantly higher than those by CCFA (pv 0.02, pv 0.04 ). There was no significant difference between alcohol shock and sodium taurocholate enrichment methods (PV 0.39).

All isolates were found to be susceptible to piperacillin / tazobactam, metronidazole, imipenem, chloramphenicol, amoxicillin + clavulanic acid, vancomycin, ampicillin and resistant to ciprofloxacin, gentamicin and colistin. The isolates were susceptible to cefotaxime (85.7\%), erythromycin $(87.1 \%)$, rifampin $(74.2 \%)$, tetracycline $(41.4 \%)$, and clindamycin (32.8\%). The MIC of vancomycin varied from 0.19 to $2 \mu \mathrm{g} / \mathrm{mL}$, whereas that of metronidazole varied from 0.38 to $2 \mu \mathrm{g} / \mathrm{mL}$. Seventeen $(24.28 \%)$ and $53(75.72 \%)$ isolates were resistant to three and four or more antibiotics, respectively. Phenotypic typing of $70 \mathrm{C}$. difficile isolates based on seven resistance patterns are shown in Table 1.

\section{DISCUSSION}

The most commonly drugs used to treat diseases associated with $C$. difficile are metronidazole and vancomycin. Most clinical laboratories assume that all $C$. difficile strains are susceptible to metronidazole and vancomycin. However, in Spain a 6.3\% rate resistance to metronidazole $(16 \mu \mathrm{g} / \mathrm{mL})$ among isolates of $C$. difficile was reported (Pelaez et al., 2002). Wong et al in 1999 reported about a clinical isolate highly resistant to metronidazole (MIC $64 \mu \mathrm{g} / \mathrm{mL}$ ), although the other 99 C. difficile tested had MIC $<2 \mu \mathrm{g} / \mathrm{mL}$. Pelaez et al in 2002 reported the highest rate of metronidazole resistance in 
Table 1. Phenotypic typing of $70 \mathrm{C}$. difficile isolated from different sources based on resistance patterns.

\begin{tabular}{|c|c|c|c|c|c|c|}
\hline \multirow[b]{2}{*}{$\begin{array}{l}\text { Resistance } \\
\text { patterns }\end{array}$} & \multirow[b]{2}{*}{$\begin{array}{l}\text { Antibiotic } \\
\text { resistance }\end{array}$} & \multicolumn{5}{|c|}{ NO of patterns isolated from } \\
\hline & & $\begin{array}{c}\begin{array}{c}\text { Total } \\
\text { isolates }\end{array} \\
\end{array}$ & Staff & Environment & $\begin{array}{l}\text { Patients at } \\
\text { admission }\end{array}$ & $\begin{array}{c}\text { Patients after } 7 \text { days } \\
\text { hospitalization }\end{array}$ \\
\hline P1 & ${ }^{*} \mathrm{~A},{ }^{* *} \mathrm{~B}, \mathrm{RP}$ & $5 / 70$ & $2 / 18$ & ${ }^{2} \mathrm{NI}$ & $1 / 16$ & $1+1 / 22$ \\
\hline P2 & $A, B$ & $17 / 70$ & $3 / 18$ & $\mathrm{NI}$ & $6 / 16$ & $2+6 / 22$ \\
\hline P3 & $\mathrm{A}, \mathrm{B}, \mathrm{CD}, \mathrm{T}$ & $29 / 70$ & $5 / 18$ & $12 / 14$ & $5 / 16$ & $2+5 / 22$ \\
\hline P4 & $\mathrm{A}, \mathrm{B}, \mathrm{RP}, \mathrm{T}$ & $7 / 70$ & $2 / 18$ & $1 / 14$ & $2 / 16$ & $2 / 22$ \\
\hline P5 & $A, B, C D$ & $4 / 70$ & $3 / 18$ & $1 / 14$ & $\mathrm{NI}$ & $\mathrm{NI}$ \\
\hline P6 & $A, B, C D, C T X$ & $5 / 70$ & $1 / 18$ & $\mathrm{NI}$ & $2 / 16$ & $2 / 22$ \\
\hline P7 & $\mathrm{A}, \mathrm{B}, \mathrm{T}, \mathrm{E}$ & $3 / 70$ & $2 / 18$ & $\mathrm{NI}$ & $\mathrm{NI}$ & $1 / 22$ \\
\hline
\end{tabular}

$\mathrm{RP}=$ Rifampin $(5 \mu \mathrm{g}), \mathrm{CD}=$ Clindamicin $(2 \mu \mathrm{g}), \mathrm{T}=$ Tetracycline $(30 \mu \mathrm{g}), \mathrm{CTX}=$ Cefotaxime $(30 \mu \mathrm{g}), \mathrm{E}=\mathrm{Erythromycin}(15 \mu \mathrm{g})$. ${ }^{*} \mathrm{~A}$ group=Susceptible to Metronidazole $(5 \mu \mathrm{g})$, Vancomycin $(30 \mu \mathrm{g})$, Chloramphenicol (30 $\mu \mathrm{g})$, Imipenem (10 $\mu \mathrm{g})$, Ampicillin (10 $\mu \mathrm{g}$ ), Piperacillin/tazobactam $(100 / 10 \mu \mathrm{g})$, Amoxyclav $(30 \mu \mathrm{g}) .{ }^{* *} \mathrm{~B}$ group = Resistant to Colistin $(25 \mu \mathrm{g})$, Gentamicin (120 $\left.\mu \mathrm{g}\right)$, Ciprofloxacin (5 $\mu \mathrm{g}) .{ }^{* * *} \mathrm{NI}=$ Not isolated. Hospital acquired isolates are shown in bold numbers.

HIV-infected patients. The new antibiotics against $C$. difficile with reduced susceptibility to vancomycin were also tested (Pelaez et al., 2005). In 1991, the first isolate of $C$. difficile not susceptible to vancomycin appeared in Poland but the study was performed by a disk diffusion method (Dworczynski et al., 1991). The first isolates of $C$. difficile not susceptible to vancomycin appeared in Spain in 1996, although none showed full resistance to these agents (Pelaez et al., 2002). On the other hand, among 193 C. difficile strains isolated in Poland between 1998 and 2003, resistance to metronidazole and vancomycin was not observed (Pituch et al., 2005). All C. difficile isolates were reported to be sensitive to vancomycin and metronidazole (Poilane et al., 2007). Pituch et al also did not report resistance to vancomycin and metronidazole in 2003. In our study, all isolates were found to be susceptible to metronidazole and vancomycin by both Etest and disc diffusion methods but prevalence of resistant to other antimicrobial agents is highly variable like other studies in different populations and different countries, from 0 to $100 \%$ (Poilane et al., 2007, 2008; Huang et al., 2009; Cattoir et al., 2008).

In this research a total of seven different antibiotic resistant patterns were identified, among which type P3 was the commonest type overall and was isolated from each group of samples $(41.43 \%)$, followed by resistance type P2 (24.28\%), P4 (10\%), P6 and P1 (7.15\%), P5 $(5.72 \%)$ and P7 (4.28\%) (Table 1), indicating that, transmission and colonization of $C$. difficile could happen among patients, staff and environment but the severity of the infection will depends on the own patient's vulnerability to infection.

Among patients who are being hospitalized, some new strains are usually introduced by colonized patient and transmitted to other patients or to the environment, thus, colonized and infected patients are an important reservoir of C. difficile (Fawley and Wilcox, 2001; Titov et al., 2000). Although it can occasionally spread through the air
(Best et al., 2010), the main type of transmission is via the hands of hospital staff. Our results showed that, $32 \%$ of newly hospitalized patients and $18 \%$ of staff were healthy carrier in this hospital. Indiscriminate consumption of antibiotics by patients and people who can easily buy any antibiotics without physician's prescription can be the main factor in overgrowth of $C$. difficile in their bowels, while most of staff are aware of antibiotic side effects and avoid using antibiotics freely. In addition $10.37 \%$ of environmental samples were contaminated with this bacterium, thus, $12 \%$ of hospitalized patients were colonized during seven days staying in the various wards. Although there is minimal literature regarding the transmission of $C$. difficile from hospital staff to patients, and none looking solely at doctors but the hands of hospital personnel caring for patients with $C$. difficile often become colonized with the organism, facilitating transmission among hospital inpatients (Macfarland et al., 1987). In one study, the risk of colonization was found to increase in direct proportion to the length of hospital stay, ranging from $13 \%$ among patients admitted for less than 1 week to as high as $50 \%$ among patients admitted for more than 4 weeks; this suggests that ongoing exposure to $C$. difficile occurs throughout the hospital stay (Conly, 2000). Rotimi et al in 2002 in Kuwait reported acquisition rate of $C$. difficile from 5.9 to $36 \%$ during 4 to 53 days of hospitalisation in various wards. The reason for low rate of colonization $(12 \%)$ in this research could be the kind of wards that had been studied.

The enrichment broth was chosen to provide the optimal recovery of $C$. difficile spores, based on the premise that spores would be the main form of $C$. difficile to survive suboptimal handling conditions. Bile salts such as sodium cholate and taurocholate have previously been shown to enhance the recovery of $C$. difficile by facilitating spore germination (Buggy et al., 1985) and may be particularly useful when this procedure is 
followed by alcohol shock method, especially if samples are handled under suboptimal anaerobic conditions (Marler et al., 1992). In this study the rate of recovery by $0.1 \%$ sodium taurocholate enrichment method and alcohol shock was significantly higher than those by CCFA (pv 0.02, pv 0.04) as several studies have shown nearly the same results (Arroyo et al., 2005; Marler et al., 1992).

\section{ACKNOWLEDGMENTS}

The authors would like to thank the Vice Chancellor of Tabriz University of Medical Sciences, Tabriz, Iran, for the research grant $(5 / 4 / 8748-2009 / 1 / 30)$. This research was approved by the Committee of Ethics on Research of the Tabriz University of Medical Sciences (5/4/82652009/1/16).

\section{REFERENCES}

Arroyo LG, Rousseau J, Willey BM, Low DE, Staempfli H, McGeer A, Weese JS (2005). Use of a selective enrichment broth to recover Clostridium difficile from stool swabs stored under different conditions. J. Clin. Microbiol., 43(10): 5341- 5343.

Bartlett JG (1994). Clostridium difficile: History of its role as an enteric pathogen and the current state of knowledge about the organism. Clin. Infect. Dis., 18(Suppl 4): S265-272.

Best EL, Fawley WN, Parnell P, Wilcox MH (2010). The potential for airborne dispersal of Clostridium difficile from symptomatic patients. Clin. Infect. Dis., 50(11): 1450-1457.

Buggy BP, Hawkins CC, Fekety R (1985). Effect of adding sodium taurocholate to selective media on the recovery of Clostridium difficile from environmental surfaces. J. Clin. Microbiol., 21(4): 636-637.

Cattoir V, Ould- Hocine Zf, Legrand P (2008). Antimicrobial susceptibility of Clostridium difficile clinical isolates collected from 2001 to 2007 in a French university hospital. Pathol. Biol., (Paris). 56(7-8): 407-411.

Conly JM (2000). Clostridium difficile- associated diarrhoea - The new source of the health care facility. Can. J. Infect. Dis., 11(1): 25-27.

Dworczynski I, Sokol B, Meisel- Mikotajczyk F (1991). Antibiotic resistance of Clostridium difficile isolates. Citobios., 65(262-263): 149-153.

Fawley WN, Wilcox MH (2001). Molecular epidemiology of endemic Clostridium difficile infection. Epidemiol. Infect., 26: 343-350.

Hirschhorn LR, Trnka Y, Onderdonk A, Lee ML, Platt R (1994). Epidemiology of community-acquired Clostridium difficile-associated diarrhoea. J. Infect. Dis., 169: 127-133.

Huang H, Weintraub A, Fang H, Nord CE (2009). Antimicrobial resistance in Clostridium difficile. Int. J. Antimicrob. Agents, 34(6): 516- 522.
Marler LM, Siders JA, Wolters LC, Pettigrew Y, Skitt BL, Allen SD (1992). Comparison of five cultural procedures for isolation of Clostridium difficile from stools. J. Clin. Microbiol., 30: 514-516.

McDonald LC, Owings M, Jernigan DB (2006). Clostridium difficile infection in patients discharged from US short-stay hospital. Emerg. Infect. Dis., 12(3): 409-415.

Macfarland LV, Mulligan ME, Kwok RY, Stamm WE (1989). Nosocomial acquisition of $C$. difficile infection. N. Engl. J. Med., 320(4): 204-210.

Noren T (2010). Clostridium difficile and the disease it causes. Methods. Mol. Biol., 646: 9-35.

O'Connor D, Hynes P, Cormican M, Colins E, Corbett- Feeney G, Cassidy M (2001). Evaluation of methods for detection of toxins specimens of faeces submitted for diagnosis of $C$. difficile associated diarrhoea. J. Clin. Microbiol., 39(8): 2846-2840.

Pelaez T, Alcala L, Alonso R, Martin-Lopez A, Garcia-Arias V, Marin M, Bouza E (2005). In vitro activity of ramoplanin against Clostridium difficile, including strains with reduced susceptibility to vancomycin or with resistance to metronidazole. Antimicrob. Agents Chemother., 49(3): 1157-1159.

Pelaez T, Alcala L, Alonso R, Rodriguez-Creixems M, Garcia-Lechuz JM, Bouza E (2002). Reassessment of Clostridium difficile susceptibility to metronidazole and vancomycin. Antimicrob. Agents Chemother., 46(6): 1647-1650.

Pelaez T, Cercenado E, Alcala L, Marin M, Martin-Lopez A, MartinezAlarcon J, Catalan P, Sanchez-Somolinos M, Bouza E (2008). Metronidazole resistance in $C$. difficile is heterogeneous. J. Clin. Microbiol., 46(9): 3028-3032.

Pituch $\mathrm{H}$, Obuch-Woszczatyński P, Glinka D, Łazińska B, MeiselMikołajczyk F, Łuczak M (2003). Assessment of susceptibility to metronidazole and vancomycin of Clostridium difficile strains isolated between 1998-2002. Med. Dosw. Mikrobiol., 55(3): 253-258.

Pituch H, Obuch-Woszczatynski P, Wultanska D, Meisel-Mikotajczyk F, Luczak M (2005). A survey of metronidazole and vancomycin resistance in strains of $C$. difficile isolated in Warsaw, Poland. Anaerobe., 11: 197-199.

Poilane I, Bert F, Cruaud P, Nicolas- Chanoine MH, Collignon A (2007). Interest of the disk diffusion method for screening Clostridium difficile isolates with decreased susceptibility to antibiotics. Pathol. Biol., 55(8-9): 429-433.

Poilane I, Fantinato C, Cruaud P, Collingnon A (2008). Epidemiological study of $C$. difficile strains isolated in Jean-Verdier- Rene-Muret hospitals from 2001 to 2008. Pathol. Biol., 56(7-8): 412-416.

Poxton IR, McCoubray J, Blair G (2001). The pathogenicity of Clostridium difficile. Clin. Microbiol. Infect., 7: 421-427.

Rotimi VO, Mokaddas EM, Jamal WY, Verghese TL, el-Din K, Junaid TA (2002). Hospital-acquired Clostridium difficile infection amongst ICU and burn patients in Kuwait. Med. Princ. Pract., 11(1): 23-28.

Titov L, Lebedkova N, Shabanov A, Tang YJ, Cohen SH, Silva JJr (2000). Isolation and molecular characterization of Clostridium difficile strains from patients and the hospital environment in Belarus. J. Clin. Microbiol., 38: 1200-1202.

Wong SS, Woo PC, Luk WK, Yuen KY (1999). Susceptibility testing of Clostridium difficile against metronidazol and vancomycin by disc diffusion and E-test. Diagn. Microbiol. Infect. Dis., 34: 1-6. 